\title{
When the beat clots
}

\author{
Ischemic stroke in atrial fibrillation
}

Kevin Braden (Meds 2017), Nicole Arseneau (Meds 2018)

Faculty Reviewer: Dr Allan Skanes, MD, FRCPC (Division of Cardiology)

An emergency room physician is asked to see a 68-year-old male complaining of mild chest discomfort, intermittent palpitations, and worsening shortness of breath. The patient presented to the emergency room with an acute onset of palpitations and states a 3-month history of fatigue. At triage, blood pressure is $135 / 90$ $\mathrm{mmHg}$, respiratory rate is 16 breaths per minute, and an irregular heart rate at $125 \mathrm{bpm}$ at rest is identified. Additionally, his history is notable for a 30-pack-year smoking history and longstanding, reasonably controlled hypertension. On further evaluation, the patient develops increasing confusion and light-headedness.

A 12-lead electrocardiogram (ECG) demonstrates the absence of discrete $\mathrm{P}$ waves and an irregularly irregular ventricular rate, diagnostic of atrial fibrillation. However, immediately following the identification of atrial fibrillation on ECG, the patient begins describing a weakness in his left hand. His symptoms progress over the next ten minutes until he can no longer lift his arm and has trouble speaking. Concerned, the emergency physician immediately begins assessment of ischemic stroke.

\section{THROMBOGENEISIS IN ATRIAL FIBRILLATION}

Atrial fibrillation (AF) is a supraventricular tachyarrhythmia characterized by uncoordinated atrial activation and subsequent diminution of mechanical function. ${ }^{1}$ Rapid, ectopic firing of multiple atrial foci, resulting in the asynchronous depolarization of the atria, produces the characteristic cardiac arrhythmia. Due to the rapid and chaotic atrial activity, AF leads to disorganized mechanical atrial function, irregular ventricular rate, and hemodynamic irregularities, ultimately generating a prothrombotic environment. ${ }^{2}$

The most serious complication of atrial fibrillation is a thromboembolic event, such as an ischemic stroke, which can lead to permanent neurological damage. An ischemic stroke may occur in patients with AF either as the primary presenting manifestation of AF or in patients with previously diagnosed AF despite appropriate medical management. In such patients, a cardiac embolus most frequently originating from the left atrium is thought to be a main source of ischemic strokes in patients with $\mathrm{AF}^{3}$

\section{INITIAL ASSESSMENT OF ISCHEMIC STROKE IN ATRIAL FIBRILLATION}

Atrial fibrillation is the most common cardiac arrhythmia seen in clinical practice and is an important contributor to increased morbidity and mortality, largely due to thromboembolic events such as ischemic stroke. ${ }^{4,5}$ As a result of an acute embolic obstruction to cerebral circulation, an ischemic stroke manifests with the abrupt onset of focal neurologic deficits, with symptoms of stroke remaining indefinitely if irreversible neurological damage occurs as a result of the cerebral ischemia. As such, prompt assessment and management is key when stroke is strongly suspected. Following the assessment of vital signs and ensuring the stabilization of airway, breathing, and circulation, a focused history and physical examination should be promptly obtained. ${ }^{6}$

The single most influential item with regards to patient history in stroke evaluation is the time of symptom onset, defined as the last known time when the patient was at their previous baseline or symptom-free state. ${ }^{1}$ Determining the time of ischemic stroke symptom onset is of crucial importance, and acts a main determinant of eligibility for acute intravenous thrombolysis treatment. For patients unable to provide this information at the time of presentation, consulting patient family members, bystanders, or emergency medical service personnel may be required. After identifying time of symptom onset, a thorough history and physical exam should follow, focusing on identifying the progression of symptoms, possible embolic sources, and any concomitant patient comorbidities that may impact management of an ischemic stroke. Any contraindications to thrombolytic treatment should also be assessed at this time. ${ }^{6}$

An initial neurological examination should be promptly performed following physical examination. Formal stroke evaluations, as guided by documents such as the National Institutes of Health Stroke Scale (NIHSS), have demonstrated clinical utility as a form of rapid neurological assessment, and may be administered successfully by a broad spectrum of healthcare providers. ${ }^{78}$ The three most predictive examination findings for the diagnosis of acute stroke are facial paresis, abnormal speech, and arm drift/weakness., ${ }^{910}$ Blood should be drawn to evaluate complete blood count, platelet count, blood glucose, electrolytes, cardiac markers, and coagulation studies. Furthermore, timely brain imaging remains critical to the rapid evaluation and diagnosis of patients with potential ischemic strokes. Imaging may be used to exclude the presence of intracranial hemorrhage, assess the degree of brain injury, and identify the vascular lesion responsible for the ischemic deficit. Either computed tomography or magnetic resonance imaging may be used as the initial imaging modality for the emergent assessment of patients with suspected stroke. ${ }^{6}$

The emergency physician, quickly recognizing the signs of stroke and noting the onset of stroke symptoms, immediately begins the clinical stroke evaluation using the NIHSS. Blood is drawn, immediately sent to the laboratory, and imaging studies are arranged. An urgent consult to the stroke service is made and decisions for early management are considered. 


\section{ACUTE MANAGEMENT OF ISCHEMIC STROKE}

Following the diagnosis of ischemic stroke, timely restoration of cerebral blood flow using fibrinolytic therapy is the most effective pharmacological maneuver for salvaging viable ischemic brain tissue. ${ }^{11}$ As previously mentioned, the single most influential item with regards to patient history is the time of symptom onset, in order to aid in determining the eligibility for acute intravenous fibrinolytic treatment. Additionally, any contraindications to intravenous thrombolysis must also be strictly evaluated. ${ }^{6}$

For eligible patients with acute ischemic stroke, intravenous fibrinolytic therapy in the form of intravenous recombinant tissue-type plasminogen activator (rtPA) alteplase is currently the widely accepted approach. ${ }^{12,13}$ Timely thrombolytic therapy administered within the therapeutic window, recognized as within 4.5 hours from symptom onset, has demonstrated significant reductions of long-term disability with no increase in long-term mortality. ${ }^{14,15}$ Most importantly, earlier treatment is more likely to result in favorable outcomes, further emphasizing the importance of timely emergency department evaluation and diagnosis of ischemic stroke. $^{16}$

Intracranial hemorrhage remains the major risk of intravenous rtPA treatment, with early neurological symptoms associated with intracranial hemorrhage occurring in $6.4 \%$ of patients treated with intravenous rtPA. ${ }^{17}$ Thus, strong emphasis must be placed on initial assessment and patient history to ensure appropriate selection of patients for intravenous fibrinolysis.

For patients ineligible for intravenous rtPA, a number of endovascular treatment options have become available including intra-arterial fibrinolysis, mechanical clot aspiration or retrieval, and acute angioplasty with stenting. Although these therapies may offer favourable outcomes, these alternative therapies should be pursued only in a highly selected patient population ineligible for intravenous rtPA and in centres well equipped for these modalities. ${ }^{1}$

Returning to the case, the initial investigations and imaging results return and demonstrate early signs of cerebral infarction and identify the site of thromboembolism. Additionally, the imaging results exclude any signs of intracranial hemorrhage. Without any contraindications to fibrinolytic therapy, and presenting within the narrow therapeutic window, the patient is started on intravenous rtPA and monitored closely for the next 24 hours.

\section{LONG-TERM PREVENTION OF THROMBOEMBOLISM IN ATRIAL FIBRILLATION}

Long-term management of patients with AF often involves three considerations: rate control, rhythm control, and prevention of thromboembolism. Initially, the AF management decision involves the determination between either a rate or rhythm control strategy; however, regardless of which strategy is pursued, attention must also be directed to antithrombotic therapy for prevention of thromboembolism. ${ }^{18}$

Multiple clinical strategies have been proposed to stratify the risk of ischemic stroke in patients with $\mathrm{AF}$ to determine which patients might benefit from antithrombotic therapy. A currently accepted stratification scheme, the $\mathrm{CHADS}_{2}$, integrates elements from several strategies and identifies patients which will benefit from antithrombotic therapy. The CHADS 2 scoring system is a point-based system in which 2 points are assigned for a history of stroke or transient ischemic attack, and 1 point each is assigned for the presence of cardiac failure, hypertension, diabetes, and age over 75 years. ${ }^{19}$ In patients with AF and a CHADS 2 score $\geq 1$, longterm oral anticoagulation with warfarin or a new anticoagulant, such as apixaban, dabigatran, or rivaroxaban, unless contraindicated, is recommended. Patients with a $\mathrm{CHADS}_{2}$ score of 0 , if over 65 years, still benefit from long-term oral anticoagulation, while patients with $\mathrm{AF}$ and no additional risk factors need no therapy.18 Antithrombotic therapy has been shown to successfully lower the risk of embolization in all patients with $\mathrm{AF}$, however its use is associated with an increased risk of bleeding and requires monitoring for risk of bleeding complications. ${ }^{20,21}$

Due to the rapid response and recognition of the signs of ischemic stroke by the emergency physician, the patient suffered only minimal neurological sequelae. During the recovery from his ischemic stroke, the patient is educated on his arrhythmia and metoprolol is initiated to achieve rate control. Anticoagulation is also initiated to reduce the risk of further stroke-his $\mathrm{CHADS}_{2}$ score is 3 . He is followed up by a cardiologist to review the management of his atrial fibrillation and risk for recurrent stroke. Further discussions are made to ensure proper maintenance of his hypertension and discuss future considerations for smoking cessation.

\section{REFERENCES}

1. Fuster V, Rydén LE, Cannom DS, Crijns HJ, Curtis AB, Ellenbogen KA, Halperin JL, Le Heuzey JY, Kay GN, Lowe JE, Olsson SB, Prystowsky EN, Tamargo JL, Wann S, Smith SC Jr, Jacobs AK, Adams CD, Anderson JL, Antman EM, Halperin JL, Hunt SA, Nishimura R, Ornato JP, Page RL, Riegel B, Priori SG, Blanc JJ, Budaj A, Camm AJ, Dean V, Deckers JW, Despres C, Dickstein K, Lekakis J, McGregor K, Metra M, Morais J, Osterspey A, Tamargo JL, Zamorano JL; American College of Cardiology/American Heart Association Task Force on Practice Guidelines; European Society of Cardiology Committee for Practice Guidelines; European Heart Rhythm Association; Heart Rhythm Society. ACC/AHA/ESC 2006 Guidelines for the Management of Patients with Atrial Fibrillation: a report of the American College of Cardiology/American Heart Association Task Force on Practice Guidelines and the European Society of Cardiology Committee for Practice Guidelines (Writing Committee to Revise the 2001 Guidelines for the Management of Patients With Atrial Fibrillation): developed in collaboration with the European Heart Rhythm Association and the Heart Rhythm Society. Circulation. 2006 Aug;114(7):257-354.

2. Lévy S, Breithardt G, Campbell RW, Camm AJ, Daubert JC, Allessie M, Aliot E, Capucci A, Cosio F, Crijns H, Jordaens L, Hauer RN, Lombardi F, Lüderitz B. Atrial fibrillation: current knowledge and recommendations for management. Eur Heart J. 1998 Sep;19(9):1294-320.

3. Watson T, Shantsila E, Lip GY. Mechanisms of thrombogenesis in atrial fibrillation: Virchow's triad revisited. Lancet. 2009 Jan 10;373(9658):155-66.

4. Chugh SS, Blackshear JL, Shen WK, Hammill SC, Gersh BJ. Epidemiology and natural history of atrial fibrillation: clinical implications. J Am Coll Cardiol. 2001 Feb;37(2):371-8.

5. Benjamin EJ, Wolf PA, D’Agostino RB, Silbershatz H, Kannel WB, Levy D. Impact of atrial fibrillation on the risk of death: the Framingham Heart Study. Circulation. 1998 Sep;98(10):946-52. 
6. Jauch EC, Saver JL, Adams HP Jr, Bruno A, Connors JJ, Demaerschalk BM, Khatri P, McMullan PW Jr, Qureshi AI, Rosenfield K, Scott PA, Summers DR, Wang DZ, Wintermark M, Yonas H; American Heart Association Stroke Council; Council on Cardiovascular Nursing; Council on Peripheral Vascular Disease; Council on Clinical Cardiology. Guidelines for the early management of patients with acute ischemic stroke: a guideline for healthcare professionals from the American Heart Association/American Stroke Association. Stroke. 2013 Mar;44(3):870947.

7. Josephson SA, Hills NK, Johnston SC. NIH Stroke Scale reliability in ratings from a large sample of clinicians. Cerebrovasc Dis. 2006 Aug;22(5-6):389-95.

8. Lyden P, Raman R, Liu L, Emr M, Warren M, Marler J. National Institutes of Health Stroke Scale certification is reliable across multiple venues. Stroke. 2009 Jun;40(7):2507-11.

9. Kothari R, Hall K, Brott T, Broderick J. Early stroke recognition: developing an out-of-hospital NIH Stroke Scale. Acad Emerg Med. 1997 Oct;4(10):986-90.

10. Goldstein LB, Simel DL. Is this patient having a stroke? JAMA. 2005 May;293(19):2391-402.

11. Adams H, Adams R, Del Zoppo G, Goldstein LB; Stroke Council of the American Heart Association; American Stroke Association. Guidelines for the early management of patients with ischemic stroke: 2005 guidelines update a scientific statement from the Stroke Council of the American Heart Association/American Stroke Association. Stroke. 2005 Apr;36(4):916-23.

12. Hill MD, Buchan AM; Canadian Alteplase for Stroke Effectiveness Study (CASES) Investigators. Thrombolysis for acute ischemic stroke: results of the Canadian Alteplase for Stroke Effectiveness Study. CMAJ. 2005 May;172(10):1307-12.

13. Saver JL, Smith EE, Fonarow GC, Reeves MJ, Zhao X, Olson DM, Schwamm LH; GWTG-Stroke Steering Committee and Investigators. The "golden hour" and acute brain ischemia: presenting features and lytic therapy in $>30,000$ patients arriving within 60 minutes of stroke onset. Stroke. 2010 Jun;41(7):1431-9.

14. Hart RG, Palacio S, Pearce LA. Atrial fibrillation, stroke, and acute antithrombotic therapy: analysis of randomized clinical trials. Stroke. 2002 Nov;33(11):2722-7.

15. Del Zoppo GJ, Saver JL, Jauch EC, Adams HP Jr; American Heart Association Stroke Council. Expansion of the time window for treatment of acute ischemic stroke with intravenous tissue plasminogen activator: a science advisory from the American Heart Association/ American Stroke Association. Stroke. 2009 May;40(8):2945-8.

16. Marler JR, Tilley BC, Lu M, Brott TG, Lyden PC, Grotta JC, Broderick JP, Levine SR, Frankel MP, Horowitz SH, Haley EC Jr, Lewandowski CA, Kwiatkowski TP. Early stroke treatment associated with better outcome: the NINDS rt-PA stroke study. Neurology. 2000 Dec;55(11):1649-55.

17. The National Institute of Neurological Disorders and Stroke rt-PA Stroke Study Group. Tissue plasminogen activator for acute ischemic stroke. N Engl J Med. 1995 Dec;333(24):1581-7.

18. Verma A, Cairns JA, Mitchell LB, Macle L, Stiell IG, Gladstone D, McMurtry MS, Connolly S, Cox JL, Dorian P, Ivers N, Leblanc K, Nattel S, Healey JS; CCS Atrial Fibrillation Guidelines Committee. 2014 focused update of the Canadian Cardiovascular Society Guidelines for the management of atrial fibrillation. Can J Cardiol. 2014 Aug;30(10):111430.
19. Gage BF, Waterman AD, Shannon W, Boechler M, Rich MW, Radford MJ. Validation of clinical classification schemes for predicting stroke: results from the National Registry of Atrial Fibrillation. JAMA. 2001 Jun;285(22):2864-70.

20. Stroke Prevention in Atrial Fibrillation Investigators. Adjusted-dose warfarin versus low-intensity, fixed-dose warfarin plus aspirin for high-risk patients with atrial fibrillation: Stroke Prevention in Atrial Fibrillation III randomised clinical trial. Lancet. 1996 Sep;348(9028):633-8.

21. Gulløv AL, Koefoed BG, Petersen P. Bleeding during warfarin and aspirin therapy in patients with atrial fibrillation: the AFASAK 2 study. Atrial Fibrillation Aspirin and Anticoagulation. Arch Intern Med. 1999 Jun;159(12):1322-8.

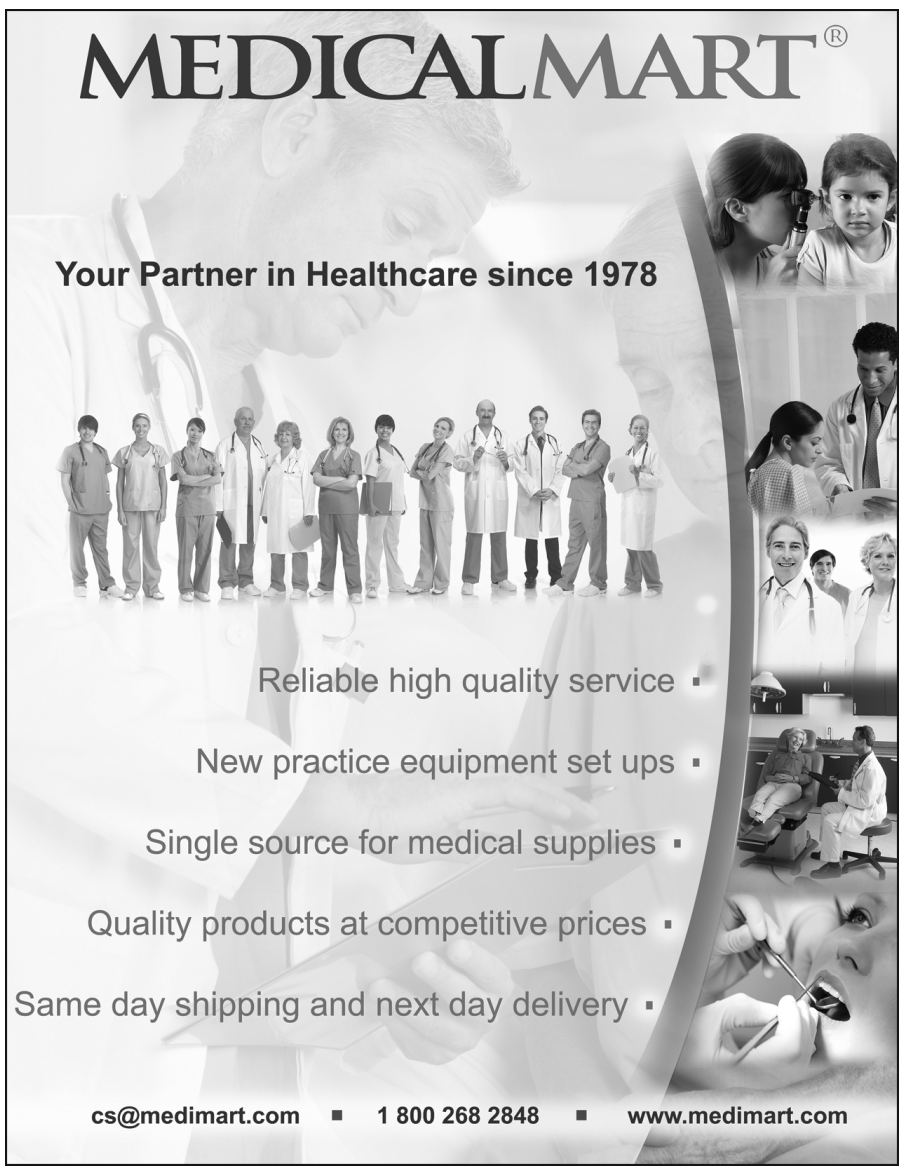

